\title{
Securitisation of Crossover Risk in Reverse Mortgages
}

\author{
Hong-Chih Huang ${ }^{\mathrm{a}}$, Chou-Wen Wang ${ }^{\mathrm{b}}$ and Yuan-Chi Miao ${ }^{\mathrm{c}}$ \\ ${ }^{a}$ Department of Risk Management and Insurance, Research Fellow of Risk and Insurance Research Center, \\ National Chengchi University, Taipei, Taiwan. \\ ${ }^{\mathrm{b}}$ Department of Risk Management and Insurance, National Kaohsiung First University of Science and \\ Technology, No. 2 Jhuoyue Road, Nanzih District, Kaohsiung 811, Taiwan. \\ ${ }^{\mathrm{c}}$ Department of Risk Management and Insurance, National Chengchi University, No. 64, Sec.2, ZhiNan \\ Road, Wenshan District, Taipei City 11605, Taiwan.
}

When the outstanding balance exceeds the housing value before the loan is settled, the insurer suffers an exposure to crossover risk induced by three risk factors: interest rates, house prices and mortality rates. With consideration of housing price risk, interest rate risk and longevity risk, we provide a three-dimensional lattice method that simultaneously captures the evolution of housing prices and short-term interest rates to calculate the fair valuation of reverse mortgages numerically. For a reverse mortgage insurer, the premium structure of reverse mortgage insurance is determined by setting the present value of the total expected claim losses equal to the present value of the premium charges. However, when the actual loss is higher than the expected loss, the insurer will incur an unexpected loss. To offset the potential loss, we also design two types of crossover bonds to transfer the unexpected loss to bond investors. Therefore, through the crossover bonds, reverse mortgage insurers can partially transfer crossover risk onto bond holders.

The Geneva Papers (2011) 36, 622-647. doi:10.1057/gpp.2011.23

Keywords: reverse mortgages; crossover risk; longevity risk; crossover bonds

\section{Introduction}

Demographic ageing represents one of the most serious challenges for developed and developing countries. The trends of mortality improvement continue to threaten the security of social security systems worldwide. The dependent ratio-defined as the ratio of the number of senior dependents (over 65 years of age) to the population between ages 15 and 64 years - keeps rising in most countries, which means that the overall economy faces a greater burden to support an ageing population.

Governments and industries seek to decrease their financial burden by deferring the retirement age and/or reducing the benefits people receive in a defined benefit pension plan. In addition, people might attain financial security in retirement through savings, purchasing private insurance or continuing to work. However, for many people who earn less from their employment, the alterative is unrealistic and impractical. As demographic shifts increase, for the group of elderly homeowners, who are often house-rich and cash-poor, reverse mortgages might provide a more practical solution. Reverse mortgages are financial contracts that allow retirees to convert their home equities into either a lump sum or an annuity, but still maintain ownership and residence until they die, sell or vacate their homes to live elsewhere. 
There are three basic payment forms for reverse mortgages: (1) tenure, (2) term or (3) line of credit. The distinguishing characteristic of the tenure mortgage is that it provides a monthly payment to the borrower as the borrower occupies the house. In contrast, a term loan provides monthly payments for only a fixed period. The credit line enables the borrower to make draws at any time up to some maximum, prespecified amount; the mortgage is not due and payable until the borrower sells the property, moves out permanently or dies. At the mortgage's due date, the loan gets repaid with accumulated interest through the sale of the property. Furthermore, the lender can only receive the minimum of the entire debt or the net value of the property, which prevents the borrower from owing more than the value of the property. This nonrecourse clause makes the reverse mortgage difficult to price.

Reverse mortgage contracts involve a range of risks from the insurer's perspective. The outstanding balance usually accumulates at a faster rate than the appreciating rate of the housing value; therefore, if the outstanding balance exceeds the housing value before the loan is settled, the lender starts to incur a loss. This crossover risk is crucial for managing reverse mortgages effectively. It can be induced by three risk factors: interest rates, housing prices and mortality rates. As proposed by Phillips and Gwin, ${ }^{1}$ an increase of the lifespan of the loan resulting from a mortality improvement incurs a higher crossover risk. A rise in interest rates speeds up the rate at which the loan accumulates, such that it may hit the crossover point earlier. In addition, a depression in the real estate market will lower the value of the home and impose a higher crossover risk.

Szymanoski ${ }^{2}$ analyses the risks involved with reverse mortgage insurance and explains a pricing model developed for the Home Equity Conversion Mortgage (HECM) - a publicly guaranteed reverse mortgage offered by the U.S. Department of Housing and Urban Development. Chinloy and Megbolugbe ${ }^{3}$ develop an alternative pricing model for a reverse mortgage in which the borrower receives payments as either a lump sum or an annuity. Both studies investigate reverse mortgages with a constant interest rate assumption. Boehm and Ehrhardt ${ }^{4}$ provide analysis of the risks associated with reverse mortgage loans and present pricing models for reverse mortgages under the interest rate risk inherent to fixed-rate reverse mortgages. They find that the interest rate risk of a reverse mortgage is greater than that of either a typical coupon bond or a regular mortgage. Mitchell and Piggott ${ }^{5}$ explore the feasibility of developing the reverse mortgage market in Japan and conclude that it has the potential to relieve the fiscal burden on traditional, state-funded retirement provisions.

Rodda et al. $^{6}$ analyse the HECM programme, using a simulation model in which interest rates and house prices vary according to historically accurate transition probabilities followed by the one-year Treasury rate since April 1953 and the Office of Federal Housing Enterprise Oversight house price index since 1975. Ma et al. ${ }^{7}$ analyse

\footnotetext{
${ }^{1}$ Phillips and Gwin (1992).

2 Szymanoski (1994).

${ }^{3}$ Chinloy and Megbolugbe (1994).

${ }^{4}$ Boehm and Ehrhardt (1994).

${ }^{5}$ Mitchell and Piggott (2004).

${ }^{6}$ Rodda et al. (2004).

${ }^{7}$ Ma et al. (2007).
} 
the risk of government-insured reverse mortgages in Korea. They apply a Monte Carlo simulation method, with housing prices following a geometric Brownian motion $(\mathrm{GBM})$ and interest rates following the Vasicek process. Employing the Lee-Carter model with permanent jump effects and an ARIMA-GARCH housing pricing model, Chen et al. ${ }^{8}$ price the non-recourse provision of reverse mortgages and compare it with calculated mortgage insurance premiums.

The loan balance of reverse mortgages may grow to exceed the property value at the time of termination because of multiple risks: termination risk (longevity risk), interest rate risk and housing price risk. However, most existing literature on risk modelling in the HECM programme does not simultaneously consider the dynamics of mortality rates, interest rates and housing prices. To fill this gap and address interest rate risk, housing price risk and longevity risk, we price reverse mortgages with up-to-date methods. Specifically, we consider a reverse mortgage structured like an HECM scheme and assume that the housing price follows a GBM process; ${ }^{9}$ the interest rate reflects the lognormal process proposed by Black et al. ${ }^{10}$ and the mortality-related risk can be assessed by the Lee-Carter model.

However, when the process for the short-term interest rate follows the lognormal process, the closed-form solutions of reverse mortgages are not available. Therefore, we use a three-dimensional lattice method that can simultaneously capture the evolution of housing prices and short-term interest rates to calculate a fair valuation of reverse mortgages. For the housing price process, we use the Cox-Ross-Rubinstein $(\mathrm{CRR})^{11}$ model to generate the possible states of future housing price. For short-term interest rates, we use the Black-Derman-Toy (BDT) ${ }^{10}$ model to generate the possible states of future spot rates.

Securitisation is a financial innovation that emerged in the 1970s in the U.S. financial market. According to Cowley and Cummins, ${ }^{12}$ it involves the isolation of a pool of assets or rights to a set of cash flows and the repackaging of the assets or cash flows into securities that are traded in capital markets. The idea of securitising mortality and/or longevity risks also has been introduced. ${ }^{13}$ There is increased interest in modelling these types of mortality-based securities; hence, prior literature has proposed the ideas of mortality bonds and mortality swaps, ${ }^{14}$ which in turn have been effectively put into practice. Following an approach similar to that used by Lin and Cox ${ }^{14}$ Wang et $a l .{ }^{15}$ propose a securitisation method to hedge the longevity risk by using survivor bonds and survivor swaps for reverse mortgage products.

Also in line with Lin and Cox, Denuit et al. and Wang et al., ${ }^{16}$ we propose a securitisation method based on crossover bonds to hedge the crossover risk inherent in

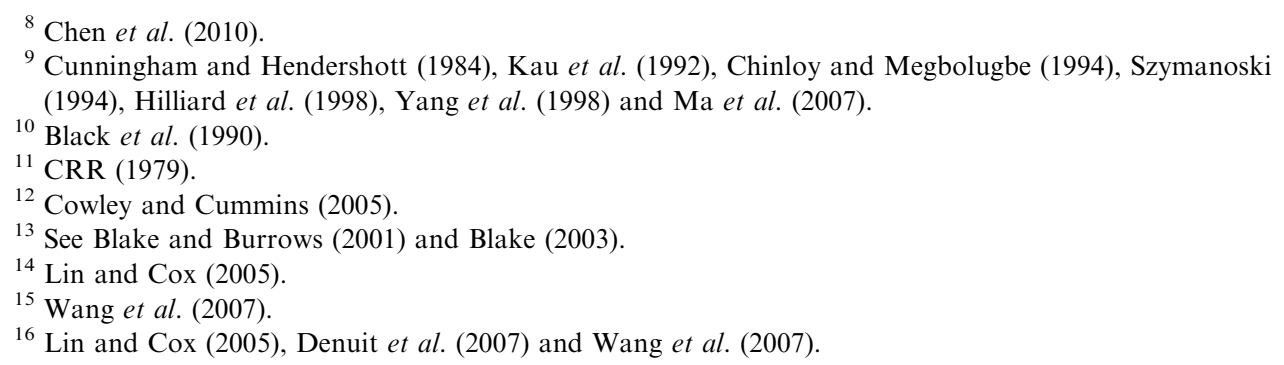


reverse mortgage products. The present value of expected premiums should equal the present value of expected claim losses under the actuarial equivalence principle. However, when the crossover risk increases due to the unexpected shocks in housing prices, interest rates or mortality rates, the actual loss may be larger than the expected one, which creates an unexpected loss for the insurer. Therefore, we design principalguaranteed crossover bonds to transfer the unexpected loss partly onto bond investors. The payoff structure of principal-guaranteed crossover bonds relates to the actual and expected losses of reverse mortgages. At each payment date, if the actual loss of the reverse mortgage is less than the expected loss, bond investors can obtain a higher coupon rate; otherwise, they receive a lower coupon rate level. Therefore, through principal-guaranteed crossover bonds, reverse mortgage insurers can partly transfer the unexpected loss onto bond holders. In addition, both the principal guaranteed feature and the possibility of higher coupon rates inspire risk-averse investors to purchase these bonds. This win-win situation offers a solution to the issue of crossover bonds. Using a three-dimensional lattice method, we also numerically calculate fair coupon rates for crossover bonds.

\section{Pricing model of reverse mortgage insurance contracts}

In this section, we first describe the contract structure of reverse mortgages, which provides the basis for our valuation. We then model the dynamics of the spot interest rates, housing prices and mortality rates sequentially.

\section{Reverse mortgage contracts}

In the U.S. HECM programme, borrowers are required to pay 2 per cent of housing values as an upfront mortgage insurance premium $\left(U P_{0}\right)$, as well as a monthly mortgage insurance premium $\left(M I P_{t}\right)$, according to the annual rate of 0.5 per cent of the outstanding loan balances. Using this predetermined insurance premium structure, we evaluate the present value of expected claim losses and insurance premiums, thus determining the loan-to-value (LTV) ratios in a condition in which the present values of expected claim losses are equal to those of insurance premiums.

We investigate reverse mortgages with a lump sum payment, analogous to the U.S. HECM programme. ${ }^{2}$ The initial property value, denoted $H_{0}$, enables us to determine the lump sum payment. We assume that the loan becomes due and payable only at the borrower's death. The borrower receives a lump sum payment, $B A L_{0}$, and does nothing else, because the house is his or her principal residence. The value of $B A L_{t}$, or the outstanding balance at time $t$, is determined by the outstanding balance at time $t-1$ plus the premium charge with interest accrued. Thus $B A L_{t}$ can be calculated as follows:

$$
B A L_{t}=\left(B A L_{t-1}+M I P_{t}\right)(1+y)
$$

where

$$
\begin{aligned}
B A L_{t} \equiv & \text { The outstanding loan balance at time } t, \\
& B A L_{0}=M \cdot H_{0}+U P_{0}=M \cdot H_{0}+0.02 H_{0}=(M+0.02) H_{0} .
\end{aligned}
$$


626

$M \equiv$ Maximum level of mortgages (as a percentage).

$U P_{0} \equiv$ Upfront mortgage insurance premium at inception.

$M I P_{t} \equiv$ Yearly mortgage insurance premiums at time $t$, $M I P_{t}=0.005 B A L_{t-1}$.

$y \equiv$ Mortgage interest rate at time $t$.

We can recursively obtain the expressions for $M I P_{t}$ and $B A L_{t}$, as follows:

$$
B A L_{t}=1.005^{t}(M+0.02)(1+y)^{t} H_{0},
$$

and

$$
\begin{aligned}
M I P_{t} & =0.005 B A L_{t-1} \\
& =0.005 \times 1.005^{t-1}(M+0.02)(1+y)^{t-1} H_{0} .
\end{aligned}
$$

From the insurer's standpoint, one of the crucial risks to manage in reverse mortgages is the crossover risk, which combines three underlying risks: interest risk, housing price risk and mortality risk. In the following sections, we describe their dynamics.

\section{Interest rate process}

Generally speaking, in an ordinary economic environment, we can assume that the short-term risk-free interest rate is constant. However, in some circumstances, the short-term interest rate changes dramatically. For example, when the central bank suddenly changes monetary policies or oil shocks occur, the short-term interest rate will fluctuate over time. Thus, instead of using a constant interest rate, we assume the short-term risk-free interest rate is stochastic.

There are a number of models of the local process for the short-term interest rate - a normal process, ${ }^{17}$ a lognormal process ${ }^{18}$ and a square-root process, ${ }^{19}$ among others. Among them, lognormal models keep the rate away from zero entirely, whereas the interest rate in the normal process may fall below zero. We use the lognormal model to describe the evolution of short-term interest rates, as follows:

$$
d \ln r_{t}=\left(\theta_{t}+\frac{\partial \ln \sigma_{t}^{r} / \partial t}{\sigma_{t}^{r}} \ln r_{t}\right) d t+\sigma_{t}^{r} d W_{t}^{r},
$$

where $r_{t}$ is the instantaneous spot rate at time $t ; \theta_{t}$ is a long-term interest rate parameter; $\sigma_{t}^{r}$ is the volatility of the spot rate at time $t$; and $W_{t}^{r}$ represents a standard Brownian motion under a risk-neutral measure $Q$. Assuming a different lognormal short rate distribution for each future time allows both mean and variance to depend on time. In contrast with the Vasicek model, in the lognormal representation, the short

\footnotetext{
${ }^{17}$ Jamshidian (1989) and Vasicek (1977).

${ }^{18}$ Dothan (1978), Black et al. (1990) and Black and Karasinski (1991).

${ }^{19}$ Cox et al. (1985).
} 
rates are lognormally distributed, with the resulting advantage that interest rates become nonnegative.

Under the risk-neutral measure $Q$, the spot rate process defined in Eq. (4) must ensure that the discounted zero coupon bond price follows a martingale, namely,

$$
P(0, T)=E_{Q}\left[\frac{P(T, T)}{B(T)}\right]=E_{Q}\left[\exp \left(-\int_{0}^{T} r_{s} d s\right)\right]
$$

where $P(t, T)$ denotes the price of a zero-coupon bond issued at time $t$ that pays US\$1 at time $T, t \leqslant T$, and $B(t)$ is the money market account at time $t$. Note that Eq. (4) is a continuous time limit of the Black-Derman-Toy one-factor model (BDT model), which incorporates two independent functions of time, $\theta_{t}$ and $\sigma_{t}^{r}$, chosen so that the model fits both the yield curve and the yield rate volatility structure. We use the spotrate tree generated by the BDT model to capture the evolution of the short-term interest rate, which ensures that Eq. (5) holds.

\section{Housing price model}

Mortgage valuations typically rely on the assumption that housing prices follow a stochastic GBM process. ${ }^{9}$ This process is also known as a continuous time limit of random walk with drift for the dynamics of an instantaneous rate of returns. Therefore, under the risk-neutral measure $Q$, the discounted housing price adheres to a martingale, as follows:

$$
H(0)=E_{Q}\left[\frac{H(T)}{B(T)}\right]=E_{Q}\left[H(T) \exp \left(-\int_{0}^{T} r_{s} d s\right)\right]
$$

where $H(t)$ is the housing price at time $t$. A solution of Eq. (6) is given by

$$
\frac{d H_{t}}{H_{t}}=r_{t} d t+\sigma_{H}\left(\rho_{H r} d W_{t}^{r}+\sqrt{1-\rho_{H r}^{2}} d W_{t}^{H}\right)
$$

where $W_{t}^{H}$, independent of $W_{t}^{r}$, is standard Brownian motion under a risk-neutral probability measure $Q ; \sigma_{H}$ is the volatility of housing returns; and $\rho_{H r}$ is the correlation coefficient between the spot rate and housing returns. The proof of Eq. (7) appears in Appendix A. Note that the volatility of housing returns is unchanged when the probability measure transforms from the real-world probability measure $P$ to the risk-neutral measure $Q$. Therefore, we can directly calibrate the volatility of housing returns by using the standard derivation of the housing return series as its estimate.

We also construct a binomial tree model to capture the housing price dynamic and the correlation coefficient between the spot rate and housing returns simultaneously. We discuss the binomial tree model in the section "Three-dimensional lattice method". 


\section{Mortality model}

Since Lee and Carter presented their original work in 1992, the Lee-Carter model has been widely used for mortality trend fitting and projection. The Census Bureau population forecast has used it as a benchmark for long-run forecasts of U.S. life expectancy. The two most recent Social Security Technical Advisory Panels have suggested that trustees should adopt this method or other methods consistent with it. ${ }^{20}$

In this article, we assess mortality-related risks using the Lee-Carter model, for which $m_{x, t}$, the mortality force at age $x$ during calendar year $t$, satisfies

$$
\ln \left(m_{x, t}\right)=\alpha_{x}+\beta_{x} k_{t}+e_{x, t},
$$

where $\alpha_{x}$ represents the age pattern of death rates; $\beta_{x}$ describes the pattern of deviations from the age $x$ profile when the parameter $k$ varies; $k_{t}$ explains the change of mortality over time $t$; and $e_{x, t}$ describes the error term, which is expected to be white noise with zero mean and a relatively small variance. ${ }^{21}$

The Lee-Carter model cannot be fitted by the ordinary least square approach, because all variables on the right-hand side of the model are unobservable. Moreover, this model is obviously over-parameterised. We use the singular value decomposition $\operatorname{method}^{22}$ to fit the solutions of the parameters. To obtain a unique solution, we impose a normalisation condition, such that the $\beta_{x}$ terms sum to unity, and the $k_{t}$ terms sum to zero, that is,

$$
\sum_{t} k_{t}=0, \text { and } \sum_{x} \beta_{x}=1 .
$$

Then $\alpha_{x}$ becomes the average value of $\ln \left(m_{x, t}\right)$. For each age group $x$, we can obtain $\hat{\beta}_{x}$ by regressing $\ln \left(m_{x t}\right)-\hat{\alpha}_{x}$ on $\hat{k}_{t}$ without a constant term. Finally, $\hat{k}_{t}$ is approximately equal to the sum over age of $\ln \left(m_{x t}\right)-\hat{\alpha}_{x}$.

Following Lee and Carter, ${ }^{22}$ we forecast future values of $k_{t}$ as follows:

$$
k_{t}=k_{t-1}+z+\varepsilon_{t},
$$

where $z$ is the drift parameter, and $\varepsilon_{t}$ is a sequence of independent and identically normal distributions with mean 0 and variance $\sigma^{2}$. The values $k_{1}, \ldots, k_{t_{0}}$ are known at time $t_{0}$, but $k_{t_{j}}$ are unknown and must be forecast, where $t_{j}=t_{0}+j$ for any natural number $j$. By virtue of Eq. (10), we have

$$
k_{t_{j}}=k_{t_{0}}+j z+\sum_{i=1}^{j} \varepsilon_{t_{i}} .
$$

Moreover, conditional on the information up to time $t_{0}, k_{t_{j}}$ is normally distributed with mean $k_{t_{0}}+j z$ and variance $j \sigma^{2}$.

\footnotetext{
${ }^{20}$ Lee and Miller (2001).

${ }^{21}$ Lee (2000).

${ }^{22}$ Lee and Carter (1992).
} 
Let $p_{x_{0}}\left(t_{0}\right)$ denote the one-year survival probability that an $x_{0}$-aged person in calendar year $t_{0}$ reaches age $x_{0}+1$. We assume that the age-specific mortality rates are constant within bands of age and time, but may vary from one band to the next. Specifically, given any integer age $x_{0}$ and calendar year $t_{0}$, we suppose that

$$
m_{x_{0}+\xi, t_{0}+\tau}=m_{x_{0}, t_{0}}, \quad \text { for } 0 \leqslant \xi, \tau<1 .
$$

Thus, the one-year survival probability can be calculated as $p_{x_{0}}\left(t_{0}\right)=\exp \left(-m_{x_{0}, t_{0}}\right)$. Let $t_{n} p_{x_{0}, t_{0}}$ denote the $n$-year survival probability that an $x_{0}$-aged person in calendar year $t_{0}$ reaches age $x_{n}=x_{0}+n$, which is

$$
{ }_{t_{n}} p_{x_{0}, t_{0}}=\exp \left(-\sum_{j=0}^{n-1} m_{x_{j}, t_{0}+j}\right)=\exp \left(-\sum_{j=0}^{n-1} \exp \left(\alpha_{x_{0}+j}+\beta_{x_{0}+j} k_{t_{0}+j}\right)\right) .
$$

The distribution function of $t_{n} p_{x_{0}, t_{0}}$ under the real-world (physical) probability measure $P$ is given by

$$
F_{t_{n}}(x)=\operatorname{Porb}_{P}\left(t_{n} p_{x_{0}, t_{0}} \leqslant x\right) .
$$

Wang $^{23}$ proposes a distortion operator to change the probability measure from the real-world probability measure $P$ to a Wang risk measure, with the following transformation:

$$
F_{t_{n}}^{\lambda}(x)=\Phi\left(\Phi^{-1}\left(F_{t_{n}}(x)\right)+\lambda\right)
$$

where $\lambda$ is a parameter called the market price of risk, and $\Phi$ is the distribution function that corresponds to the standard normal distribution. Therefore, as shown by Denuit et al., ${ }^{24}$ the expectation value of ${ }_{t_{n}} p_{x_{0}, t_{0}}$ under the Wang risk measure is defined as

$$
\begin{aligned}
S_{x_{0}}\left(t_{n}\right) & =E_{Q}\left[t_{n} p_{x_{0}, t_{0}}\right]=\int_{0}^{1}\left(1-F_{t_{n}}^{\lambda}(x)\right) d x \\
& =\int_{0}^{1}\left(1-\Phi\left(\Phi^{-1}\left(F_{t_{n}}(x)\right)+\lambda\right)\right) d x .
\end{aligned}
$$

The analytical computation of $S_{x_{0}}\left(t_{n}\right)$ according to Eq. (16) is difficult to implement. Therefore, after calibrating the parameters of the Lee-Carter model, we use a Monte Carlo simulation to obtain the expected value of the $n$-year survival probability under the Wang risk measure.

\footnotetext{
${ }^{23}$ Wang (2000).

24 Denuit et al. (2007).
} 
630

Pricing model for reverse mortgage insurance

We determine the lump sum payment $B A L_{0}$ when the present value of the insurance premiums covers the present value of expected losses from future claims. Through the pricing process, it is more convenient to set the valuation date $t_{0}$ as 0 . Thus, at the valuation date $t_{0}(=0)$, the money market account is defined by

$$
B(t)=\exp \left(\int_{0}^{t} r_{u} d u\right) .
$$

We also assume that the market is complete and without arbitrage. According to arbitrage pricing theory, the present value of reverse mortgage insurance premiums equals the present value of the expected losses from future claims under the riskneutral measure $Q$. Let $x_{0}$ be the age of the borrower at time $t_{0}$, then the present value of the reverse mortgage insurance premiums is of the form:

$$
\begin{aligned}
P V M I P & =U P_{0}+\sum_{j=1}^{T} E_{Q}\left[t_{j} p_{x_{0}, t_{0}} \frac{M I P_{t_{j}}}{B\left(t_{j}\right)}\right] \\
& =\sum_{j=1}^{T} E_{Q}\left[\left(t_{j-1} p_{x_{0}, t_{0}}-{ }_{t_{j}} p_{x_{0}, t_{0}}\right) \frac{\operatorname{Max}\left(B A L_{t_{j}}-H_{t_{j}}, 0\right)}{B\left(t_{j}\right)}\right]=P V E L,
\end{aligned}
$$

where $P V M I P \equiv$ Present value of total mortgage insurance premiums at inception (time $t_{0}$ ).

$P V E L \equiv \quad$ Present value of total claim losses at inception.

$T \equiv \quad$ The number of years that borrowers with age $x_{0}$ will live until they reach 100 years of age.

${ }_{t_{j}} p_{x_{0}, t_{0}} \equiv \quad$ The probability that a borrower of age $x_{0}$ at inception will survive to age $x_{0}+j$.

With the assumption that mortality rate and financial risk are independent, we can rewrite Eq. (18) as follows:

$$
\begin{gathered}
P V M I P=U P_{0}+0.005(M+0.02) H_{0} \sum_{j=1}^{T} 1.005^{j-1}(1+y)^{j-1} \\
P\left(t_{0}, t_{j}\right) S_{x_{0}}\left(t_{j}\right) \\
P V E L=\sum_{j=1}^{T}\left[S_{x_{0}}\left(t_{j-1}\right)-S_{x_{0}}\left(t_{j}\right)\right] C\left(t_{j}\right)
\end{gathered}
$$

where $S_{x_{0}}\left(t_{n}\right)=E_{Q}\left[t_{n} p_{x_{0}, t_{0}}\right]$, and $C\left(t_{j}\right)$ is of the form:

$$
C\left(t_{j}\right)=E_{Q}\left[\frac{\operatorname{Max}\left(B A L_{t_{j}}-H_{t_{j}}, 0\right)}{B\left(t_{j}\right)}\right] .
$$


However, when the process for the short-term interest rate follows the lognormal process defined in Eq. (4), the closed-form solutions of $C\left(t_{j}\right)$ are not available. To obtain the values of $C\left(t_{j}\right)$ numerically, there are many techniques in option pricing, such as finite difference methods, lattice or tree methods, and Monte Carlo simulation methods.

\section{Three-dimensional lattice method}

We use a three-dimensional lattice method that can simultaneously capture the evolution of housing prices and short-term interest rates. To determine the process of short-term interest rates, we use the $\mathrm{BDT}^{10}$ model to generate the possible states of future spot rates. We fit the BDT model to both the yield curve and the term structure of the yield rate volatilities. Initially, we divide the time horizon into $N$ equal segments with length $\Delta t=T / N$.

Jamshidian $^{25}$ shows that the level of the spot rate at time $t$ in the BDT model is given by $r_{t}=\phi(t) \exp \left(\sigma_{t}^{r} W_{t}^{r}\right)$, where $\phi(t)$ is a time-varying medium of the lognormal distribution for the spot rate at time $t$. As proved by Shreve's ${ }^{26}$ Theorem 3.2.1, $\sum_{k=1}^{N} X_{k} \sqrt{\Delta t}$ converges to $W_{T}^{r}$ as $\Delta t \rightarrow 0$, where $X_{k}$ is either -1 or 1 with equal probability. Therefore, we can represent the level of the spot rate at node $(i, j)$ in the tree as

and

$$
r_{i \Delta t}(j)=\phi(i) \exp \left(\sigma_{i \Delta t}^{r} j \sqrt{\Delta t}\right), \quad i=1, \ldots, N
$$

$$
j=-i,-i+2, \ldots, i-2, i
$$

such that we replace $t$ by $i \Delta t$ and $W_{t}^{r}$ by $\sum_{k=1}^{i} X_{k} \sqrt{\Delta t}=j \sqrt{\Delta t}$. We briefly sketch the methodology to fit the BDT model to both the yield curve and the yield rate volatilities in Appendix B.

For the housing price process, considering the correlation coefficient between spot rates and the housing returns, we modify the CRR model to generate possible states of future housing prices. Therefore, if $H_{0}$ is the housing value at time 0 , then after one period, at time $\Delta t$, it can rise to $u H_{0}$ or decrease to $d H_{0}$, where $u$ and $d$ represent the magnitudes of one step up or down, respectively. We thus derive the binomial tree for housing prices.

Proposition 1 Let $X_{i+1}=1(-1)$ if the spot rate goes up (down) at time $(i+1) \Delta t$ in the BDT model. Based on Eq. (7) and conditional on $r_{i \Delta t}(j)$ and $X_{i+1}$, the possible values of $H_{(i+1) \Delta t}$ are $H_{i \Delta t} u$ with probability $P_{r_{i \Delta t}(j), X_{i+1}}^{H}$ and $H_{i \Delta t} d$ with probability $1-P_{r_{i \Delta t}(j), X_{i+1}}^{H}$, where $u, d$ and $P_{r_{i \Delta t}(j), X_{i+1}}^{H}$ are defined as follows:

$$
u=\frac{1}{d}=\exp \left(\sigma_{H} \sqrt{\Delta t}\right)
$$

\footnotetext{
25 Jamshidian (1991).

${ }^{26}$ Shreve (2004).
} 
632

$$
P_{r_{i \Delta t}(j), X_{i+1}}^{H}=\frac{\exp \left(\left(r_{i \Delta t}(j)-0.5 \rho_{H r}^{2} \sigma_{H}^{2}\right) \Delta t+\rho_{H r} \sigma_{H} X_{i+1} \sqrt{\Delta t}\right)-d}{u-d} .
$$

The proof of Proposition 1 is in Appendix C. When $\rho_{H r}=0$, Eq. (24) reduces to the original upward risk-neutral probability in the CRR model. Taking the limit of the number of periods equal to infinity, the continuous time limit of the binomial tree model for a log-change of housing prices becomes the GBM process defined in Eq. (7).

We combine the BDT model and modified CRR model in Figure 1 to depict a threeperiod lattice model. When the spot rate at time $2 \Delta t$ is $r_{2 \Delta t}(0)$ and the housing price is $H_{0} d^{2}$, the probability $\mathrm{P} 9$ that both housing price and spot rate go up at the sequential period is equal to 0.5 , multiplied by $P_{r_{2 \Delta t}(0), X_{3}=1}^{H}$. The other probabilities have analogous definitions. Therefore, using the three-dimensional lattice model, we can numerically obtain the values of $C\left(t_{j}\right)$. The initial outstanding loan balance $B A L_{0}$ can be determined by setting the present value of total expected claim losses equal to the present value of the premium charges, namely, $P V M I P=P V E L$.

\section{Securitisation for reverse mortgage insurance}

Suppose the lender holds a portfolio of $L$ loans. At time 0 , all the borrowers are of different ages, ranging from 62 years to 100 years. Each borrows a lump sum against his or her home property. When the outstanding balance exceeds the housing value before the loan is settled, the insurer starts to incur a loss. Therefore, for a reverse mortgage insurer, the premium structure of reverse mortgage insurance is determined by setting the present value of total expected claim losses equal to the present value of the premium charges. However, when the actual loss is higher than the expected loss, the insurer incurs an unexpected loss. To offset the potential loss, we design a principal guaranteed crossover bond to transfer the unexpected losses induced by crossover risk to the bond investors.

The payoff structure of the crossover bond is related to the actual loss and the expected loss. Similar to Treasury bonds, the crossover bonds pay interest at each coupon payment date and the principal at maturity. Unlike Treasury bonds though, when the actual loss is less than the expected loss at the coupon payment date, the bond investors receive a higher coupon rate than that for Treasury bonds with the same maturity. Otherwise, the bond investors receive a lower coupon rate. The closed form solution of the crossover bonds are hard to derive, but using the threedimensional lattice method, we can calculate their fair values.

\section{Numerical analysis}

For the numerical analysis of the impacts of longevity risk, interest rate risk and housing price risk on the valuation of reverse mortgages, we first describe the parameters for the dynamics of the interest rate, housing price and mortality rate, then present the numerical results for the LTV ratios, as well as their sensitivity analysis. Finally, we compute the fair coupon rates of the crossover bonds with maturity of up to 30 years. 
$\mathrm{t}=0$

$$
r_{0}(0), H_{0}
$$

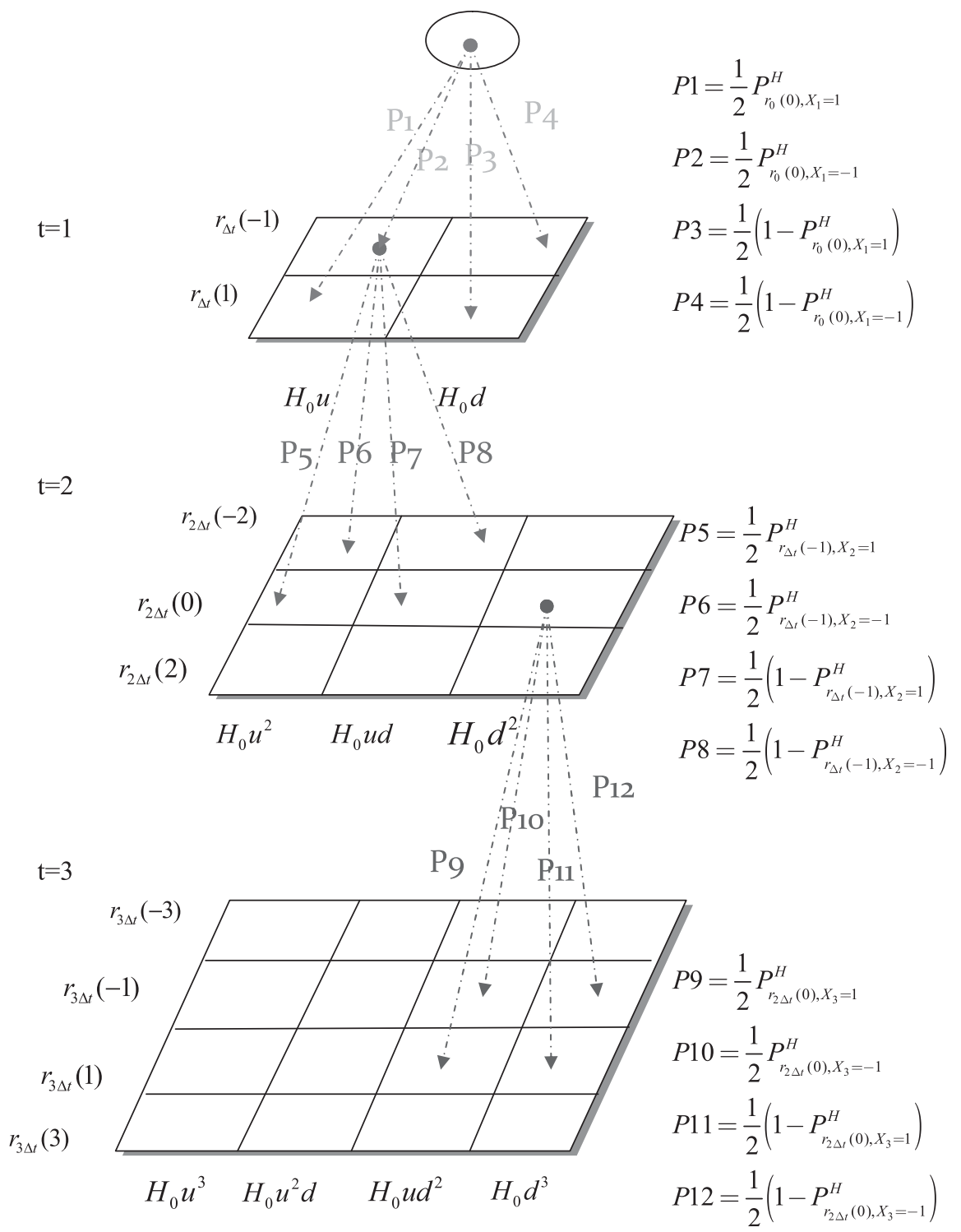

Figure 1. Three-period lattice method for pricing reverse mortgage insurance contracts.

First, we employ the daily Treasury yield curve rate data from 1 October 1993 to 31 December $2010,{ }^{27}$ obtained from the U.S. Department of the Treasury, ${ }^{28}$ to calculate

\footnotetext{
${ }^{27}$ Prior to 1 October 1993, the 20-year treasury yield rates are not available.

${ }^{28}$ www.treasury.gov/resource-center/data-chart-center/interest-rates/Pages/TextView.aspx?data=yieldAll.
} 

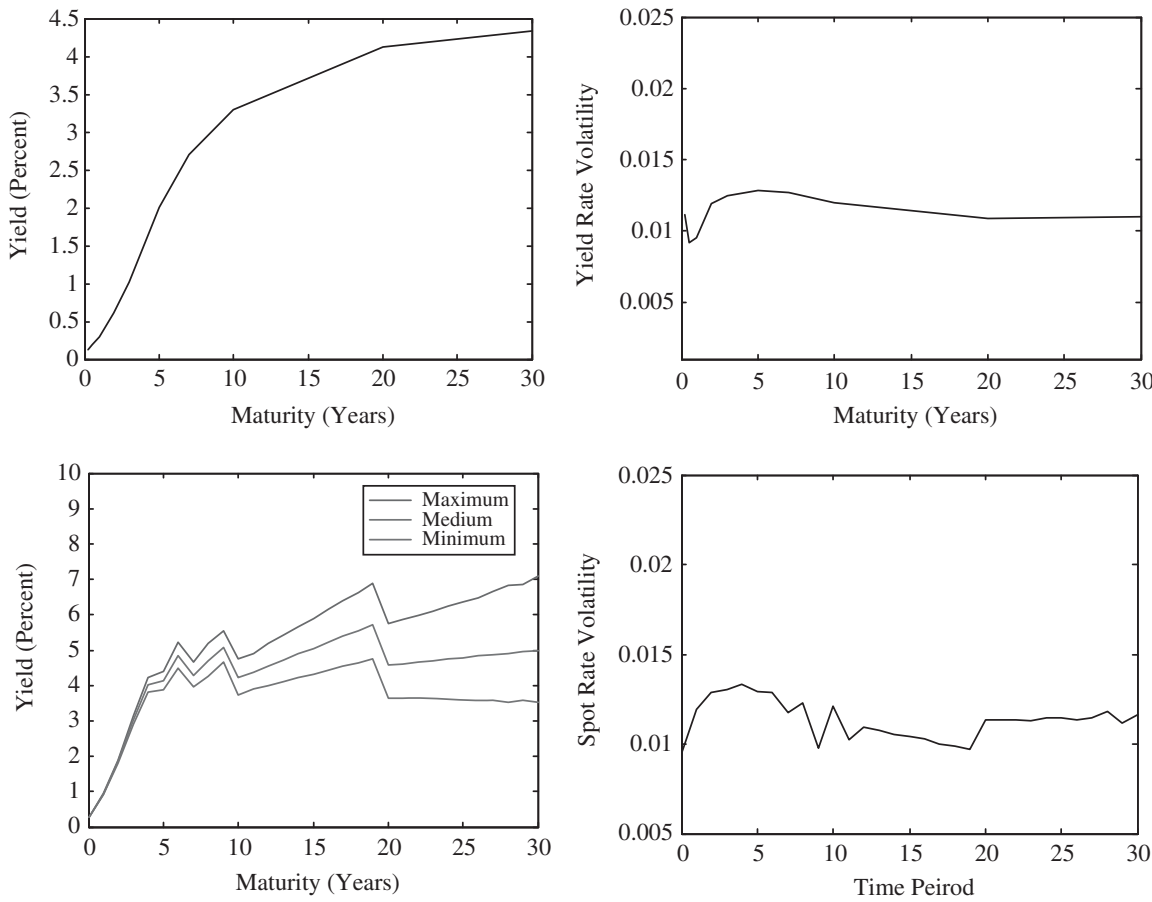

Figure 2. Calibration of the BDT model.

the volatilities of the three-month, six-month, one-year, two-year, three-year, fiveyear, seven-year, ten-year, 20-year and 30-year yield rates. The top two figures in Figure 2 are the yield curve at 31 December 2010, and its corresponding volatility structure. Fitting the BDT model to the yield curve and yield rate volatilities, we depict the minimum, medium and maximum of the spot-rate tree, together with the spot rate volatilities (see the bottom of Figure 2). Without loss of generality, we use the mediums at each time period of the BDT model as corresponding floating mortgage rates of reverse mortgages to hedge against the risk exposure to spot rate uncertainty.

We use the national average prices of previously occupied homes for conventional single-family mortgages in the U.S. as the proxy for the housing price data. ${ }^{29}$ Our sample period runs from January 1973 to December 2010, with data from the Federal Housing Financial Board. Because we assume that housing returns follow a normal distribution, the standard derivation of the housing return series, which provides an unbiased estimate of the volatility of housing returns, is 12.43 per cent. Finally, using the three-month Treasury yield rate as a proxy for the spot rate, we calculate the correlation coefficient between spot rates and housing returns as 0.0154 .

${ }^{29}$ Categories of homes include previously occupied, new and all homes. We choose previously occupied home prices as a proxy for sale price, because a reverse mortgage loan gets repaid through the proceeds of the sale of the property when the mortgagor dies. 

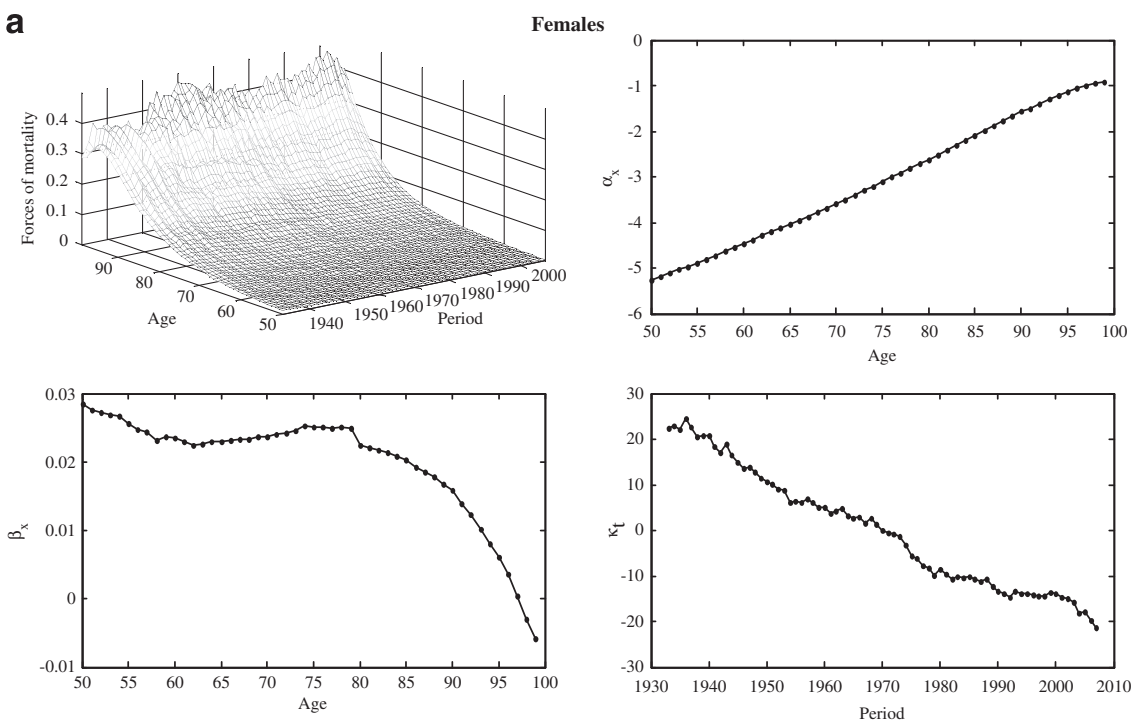

b

Males
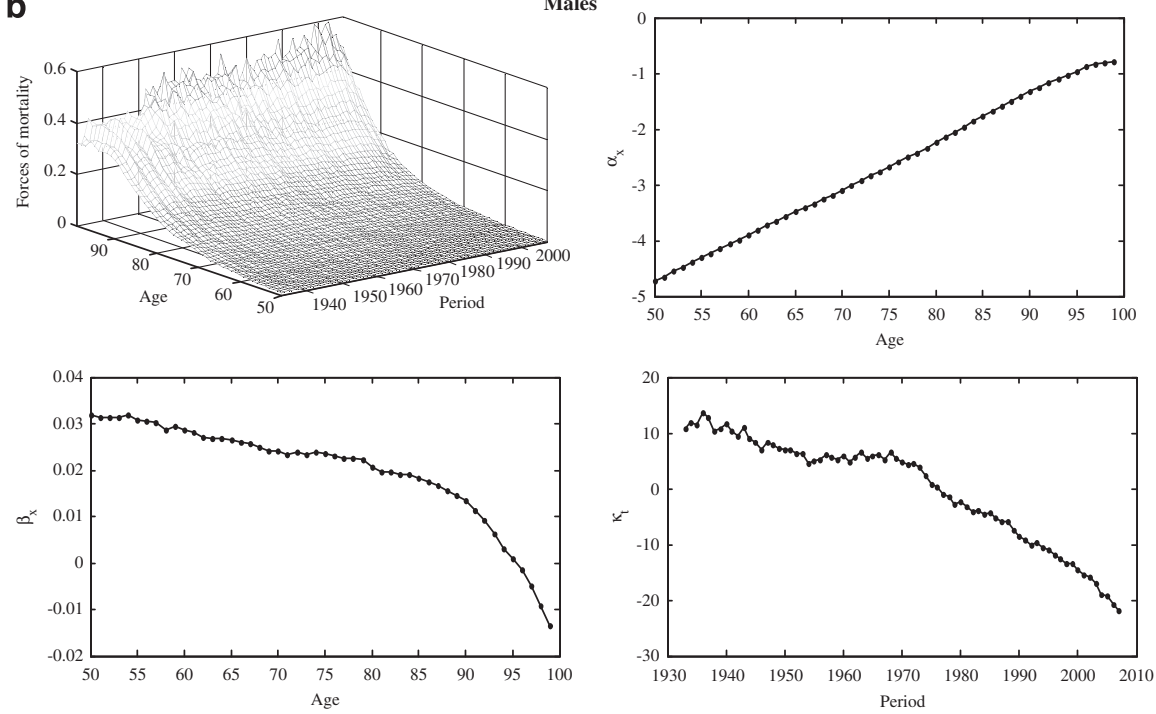

Figure 3. Calibration of the Lee-Carter model: (a) U.S. females, (b) U.S. males.

We turn to the U.S. mortality rates to calibrate the parameters of the Lee-Carter model. The data for our sample period, 1933-2007, was obtained from the Human Mortality Database website. ${ }^{30}$ The pattern of empirical mortality rates and the fitted values of $\alpha_{x}, \beta_{x}$ and $k_{t}$ appear in Figure 3. Let the market price of risk for male and

${ }^{30}$ www.mortality.org/. 

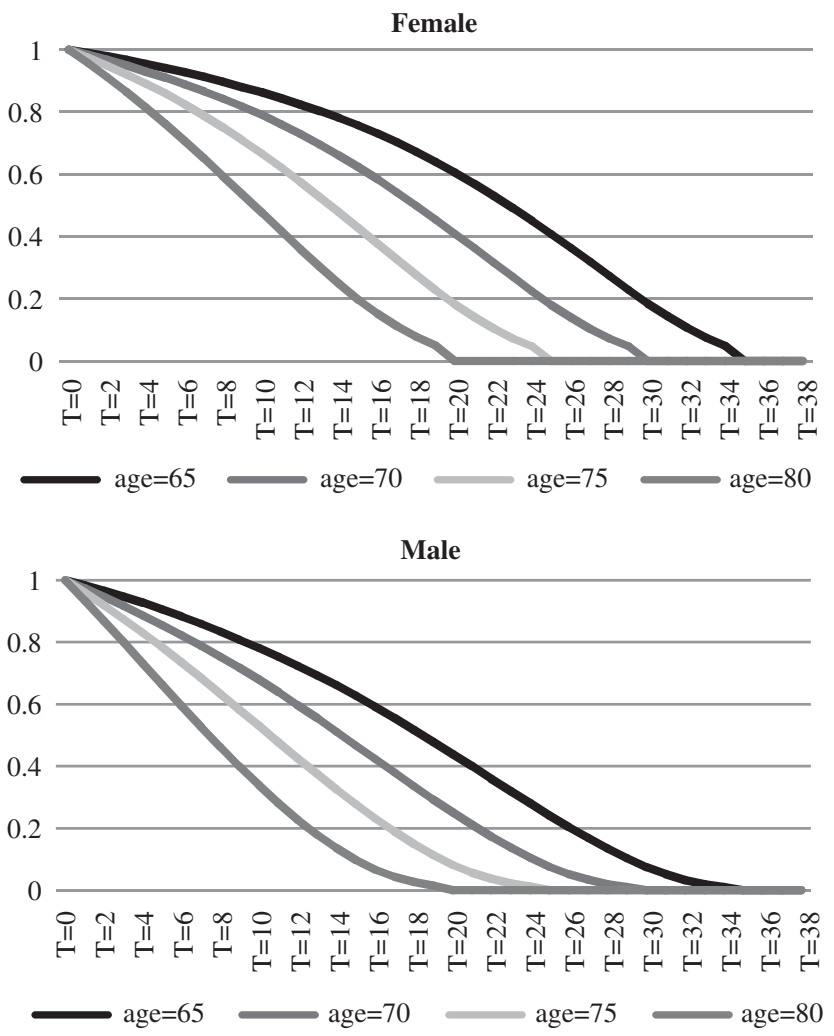

Figure 4. Survival probabilities under the Wang risk transform: (a) female, (b) male.

female mortgagees, denoted $\lambda_{M}$ and $\lambda_{F}$, be -0.5 and $-0.3,{ }^{31}$ respectively. Applying the Lee-Carter model, we depict the survival probabilities $S_{x_{0}}\left(t_{n}\right)$, according to Eq. (16), for $x_{0}=65,70,75$ and 80 in Figure 4. The higher the age, ceteris paribus, the lower is the survival probability.

Using the three-dimensional lattice method, we first present the numerical results for a representative base case. For the parameters of the base case, the initial housing value is US\$274,600, the average of previously occupied home prices in December 2010. Figure 5 depicts the LTV ratios for different ages. The lower the age is, ceteris paribus, the lower the LTV ratio. In terms of economic implications, the present value of the house is the sum of the present value of future rental incomes. According to the reverse mortgage mechanism, the borrower uses the rental income after his or her death in exchange for the lump sum payment at the inception. An older borrower can borrow more money, because his or her expected death is sooner, and the present value of the rental income after death is greater.

${ }^{31}$ Using the market price of an annuity sold to a 65-year-old individual in Belgium, Denuit et al. (2007) find that $\lambda_{M}$ ranges from 0.4901 to 0.4449 and $\lambda_{F}$ range from 0.3080 to 0.2795 . We also calculate the LTV ratios in Table 2 by varying the market price of risk from -0.5 to -0.3 for comparison. 


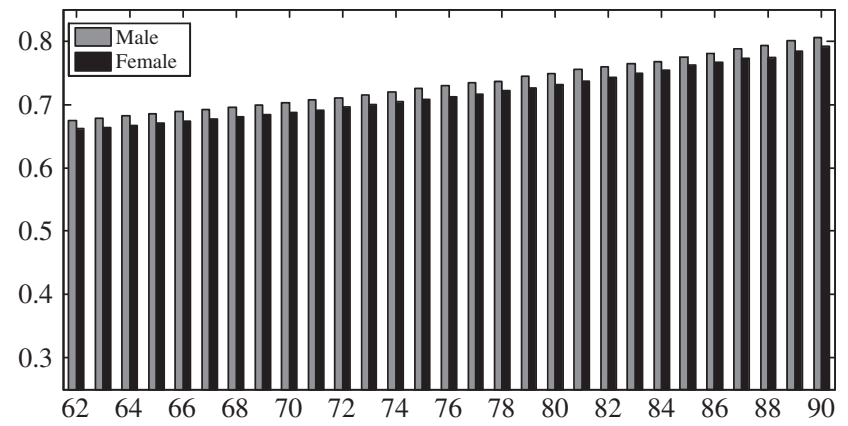

Figure 5. Loan-to-value ratios for different ages.

Table 1 Loan-to-value ratios

\begin{tabular}{|c|c|c|c|c|c|c|}
\hline \multicolumn{2}{|l|}{ Volatility } & \multirow[t]{2}{*}{ Gender } & \multicolumn{4}{|c|}{ Age (years) } \\
\hline Housing price & Interest rate & & 65 & 70 & 75 & 80 \\
\hline \multirow[t]{6}{*}{0.0932} & \multirow[t]{2}{*}{ Lower } & Female & 0.8122 & 0.8178 & 0.8252 & 0.8354 \\
\hline & & Male & 0.8172 & 0.8238 & 0.8321 & 0.8433 \\
\hline & \multirow[t]{2}{*}{ Normal } & Female & 0.8115 & 0.8174 & 0.8250 & 0.8353 \\
\hline & & Male & 0.8167 & 0.8235 & 0.8319 & 0.8432 \\
\hline & \multirow[t]{2}{*}{ Higher } & Female & 0.8107 & 0.8169 & 0.8247 & 0.8352 \\
\hline & & Male & 0.8161 & 0.8232 & 0.8318 & 0.8431 \\
\hline \multirow[t]{6}{*}{0.1243} & \multirow[t]{2}{*}{ Lower } & Female & 0.6692 & 0.6861 & 0.7064 & 0.7303 \\
\hline & & Male & 0.6834 & 0.7016 & 0.7224 & 0.7472 \\
\hline & \multirow[t]{2}{*}{ Normal } & Female & 0.6686 & 0.6858 & 0.7063 & 0.7302 \\
\hline & & Male & 0.6830 & 0.7014 & 0.7223 & 0.7471 \\
\hline & \multirow[t]{2}{*}{ Higher } & Female & 0.6679 & 0.6854 & 0.7061 & 0.7301 \\
\hline & & Male & 0.6826 & 0.7011 & 0.7222 & 0.7471 \\
\hline \multirow[t]{6}{*}{0.1554} & \multirow[t]{2}{*}{ Lower } & Female & 0.5398 & 0.5652 & 0.5963 & 0.6303 \\
\hline & & Male & 0.5602 & 0.5883 & 0.6185 & 0.6549 \\
\hline & \multirow[t]{2}{*}{ Normal } & Female & 0.5394 & 0.5649 & 0.5961 & 0.6302 \\
\hline & & Male & 0.5599 & 0.5882 & 0.6184 & 0.6548 \\
\hline & \multirow[t]{2}{*}{ Higher } & Female & 0.5390 & 0.5647 & 0.5960 & 0.6302 \\
\hline & & Male & 0.5595 & 0.5880 & 0.6184 & 0.6548 \\
\hline
\end{tabular}

Notes: We examine the sensitivity of the LTV ratios by varying the housing price volatility from $0.1243 \times 0.75=0.0932$ to $0.1243 \times 1.25=0.1554$. The lower (higher) case in the second column represents the interest rate volatilities, equal to the estimated volatilities multiplied by $0.75(1.25)$.

We next examine the sensitivity of the LTV ratios by varying the level of housing price volatility and interest rate volatility in Table 1 . From Table 1, we recognise that the higher the interest rate volatility, the lower the LTV ratio is. Higher interest rate volatility also may lead to a higher interest rate and thus a lower present value of the house, as well as a lower LTV ratio. Similarly, because higher housing price volatility 

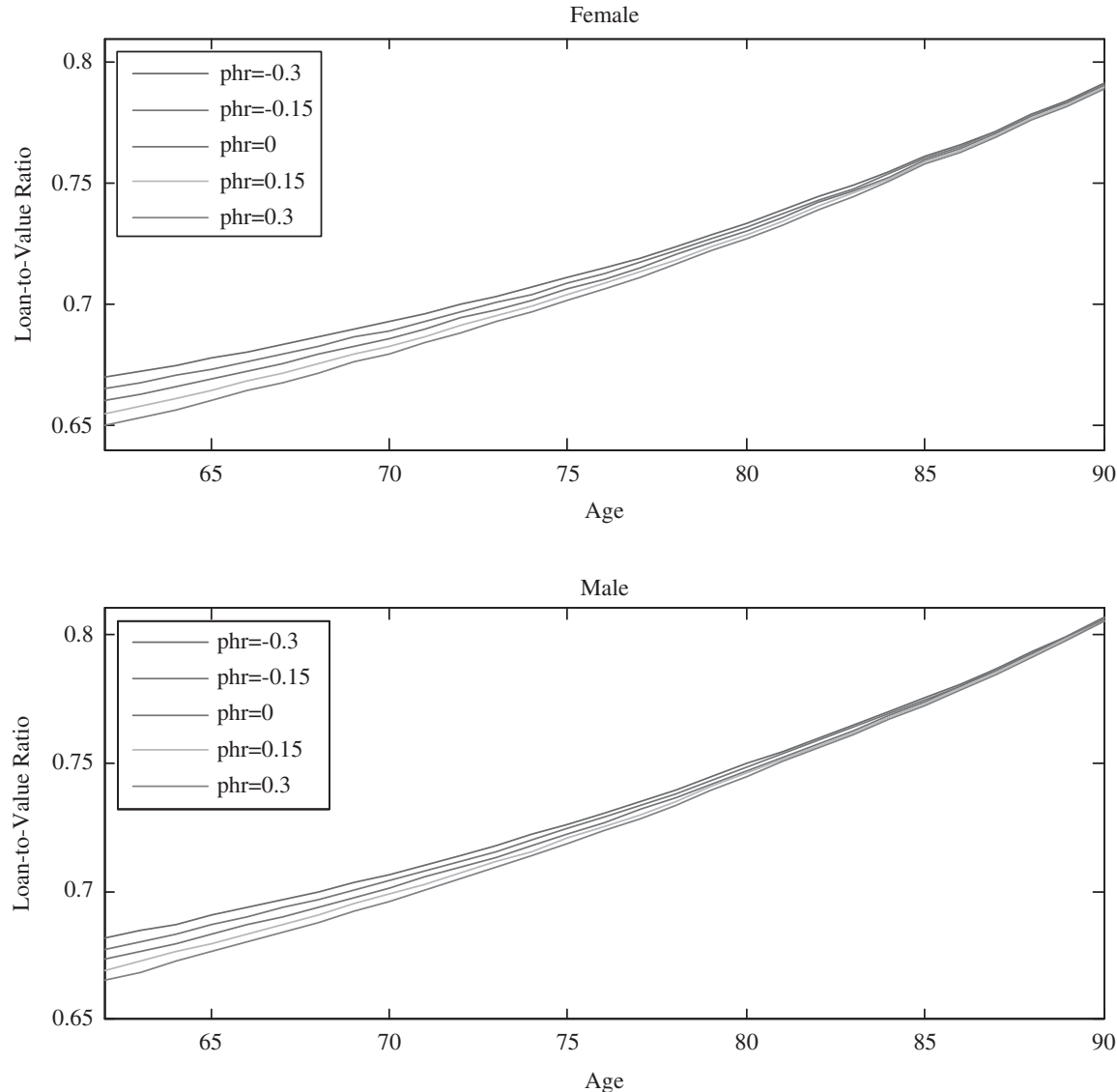

Figure 6. Loan-to-value ratios for different correlation coefficients: (a) female, (b) male.

may contribute to a lower level of housing prices, greater housing price volatility leads to a lower LTV ratio.

In Figure 6, we depict the LTV ratios when we vary the correlation coefficient between the interest rate and housing price from -0.3 to 0.3 . The higher the correlation is, the lower the LTV ratio. Therefore, both higher correlation coefficients and higher volatilities in the spot rate and housing returns contribute to a higher risk profile in the reverse mortgage, which leads to lower LTV ratios. The floating mortgage rates for reverse mortgages also mean that the impact of housing price volatility is more significant than that of the correlation and interest rate volatility on the LTV ratio, and therefore for pricing an adjusted-rate reverse mortgage, it is crucial to estimate the volatility of housing price precisely.

In Table 2, we examine the sensitivity of the LTV ratios by varying the level of market price of risk for men and women. These results reveal that the higher the market price of risk, the higher is the LTV ratio. This higher market price of risk also contributes to a lower survival probability, which in turn leads to a higher LTV ratio. 
Table 2 Loan-to-value ratios with different market price of risk

\begin{tabular}{|c|c|c|c|c|c|}
\hline & & \multicolumn{4}{|c|}{ Age (years) } \\
\hline & & 65 & 70 & 75 & 80 \\
\hline & $\lambda_{F}$ & & & & \\
\hline \multirow[t]{4}{*}{ Female } & -0.3 & 0.6686 & 0.6858 & 0.7063 & 0.7302 \\
\hline & -0.4 & 0.6684 & 0.6856 & 0.7061 & 0.7300 \\
\hline & -0.5 & 0.6682 & 0.6854 & 0.7059 & 0.7299 \\
\hline & $\lambda_{M}$ & & & & \\
\hline \multirow[t]{3}{*}{ Male } & -0.3 & 0.6834 & 0.7018 & 0.7227 & 0.7474 \\
\hline & -0.4 & 0.6832 & 0.7016 & 0.7225 & 0.7473 \\
\hline & -0.5 & 0.6830 & 0.7014 & 0.7223 & 0.7471 \\
\hline
\end{tabular}

However, compared with the volatility of housing returns, the impact of the market price of risk is trivial.

For the securitisation of the reverse mortgage, we assume the payoff structure of the principal guaranteed crossover bond relates to actual and expected losses. The actual loss at each period is calculated according to the distribution of borrowers' age and gender, as follows:

$$
A L_{t}=\sum_{g=f \text { or }} \sum_{m=62}^{90} w_{g} w_{x} A L_{t}^{g, x}
$$

where $A L_{t}$ is the actual loss at time $t ; w_{g}$ is the gender weight; $w_{\text {age }}$ is the age weight; and $A L_{t}^{f, x}\left(A L_{t}^{m, x}\right)$ is the actual loss for a woman (man) of age $x$ that satisfies:

$$
A L_{t_{j}}^{g, x_{0}}={ }_{t_{j-1}} \mid q_{x_{0}}^{g} \frac{\operatorname{Max}\left(B A L_{t_{j}}^{g, x_{0}}-H_{t_{j}}, 0\right)}{B\left(t_{j}\right)},
$$

where ${ }_{t_{j-1}} \mid q_{x_{0}}^{g}={ }_{t_{j-1}} p_{x_{0}, t_{0}}^{g}-{ }_{t_{j}} p_{x_{0}, t_{0}}^{g}$ denotes that the person has lived for $t_{j-1}$ years and will die within one year. Using the three-dimensional lattice method, we can calculate the actual losses, together with the expected losses, for different ages in each period.

The payoff structure of the first type of crossover bond (Type I) is defined as follows: similar to the case of Treasury bonds, bond investors receive the interest at each coupon payment date and the principal at maturity. However, unlike Treasury bonds, when the actual loss is larger than the expected loss at the coupon payment date, bond investors receive a coupon rate equal to 0.5 per cent. Otherwise, the bond investors receive a higher coupon rate than that of the Treasury bonds with the same maturity. In addition, according to the gender and age distribution of HECM loan borrowers, ${ }^{32}$ the female weight is assumed to be 0.6 , and the age weights $w_{x}$ are as given in Figure 7. Using the three-dimensional lattice method, in Table 3, we calculate

${ }^{32}$ Bishop and Shan (2008). 


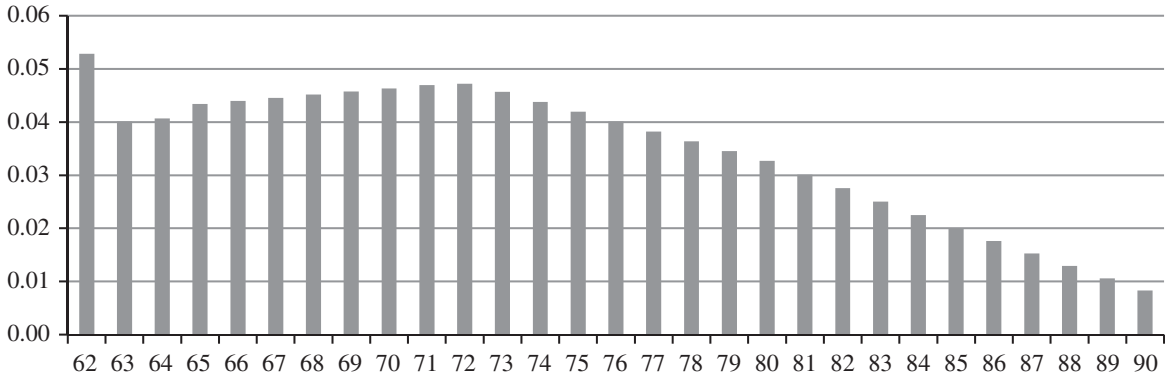

Figure 7. Age distribution for crossover bonds.

Table 3 Fair coupon rates of crossover bonds (Type I)

\begin{tabular}{lcccc}
\hline $\begin{array}{c}\text { Time to } \\
\text { maturity }\end{array}$ & \multicolumn{2}{c}{$\begin{array}{c}\text { Coupon rate } \\
\text { Actual loss }>\text { Expected } \\
\text { loss }(\%)\end{array}$} & $\begin{array}{c}\text { Corresponding } \\
\text { zero rate (\%) }\end{array}$ & $\begin{array}{c}\text { Markup } \\
(\text { bps })\end{array}$ \\
\cline { 2 - 5 } & 0.50 & 3.85 & 3.30 & +55.26 \\
10 & 0.50 & 4.86 & 4.13 & +72.80 \\
20 & 0.50 & 5.22 & 4.34 & +88.22 \\
30 & & & & \\
\hline
\end{tabular}

the fair coupon rates of the principal-guaranteed crossover bonds with different time to maturities. As the time to maturity increases, both the coupon rate and the markup increase. Therefore, when the actual loss is larger than the expected loss at the coupon payment date, the issuer of a crossover bond can partially hedge the unexpected loss, and bond holders receive a minimum coupon rate and principal at maturity. Otherwise, the crossover bond holders can receive a higher coupon than the Treasury bond with the same time to maturity. This win-win situation should make the bond attractive, such that issuers can transfer the crossover risk to the bond market.

Again using the three-dimensional lattice method, we depict the expected losses for the next 30 years in Figure 8. According to the age weights in Figure 7, the expected losses are greater than the average mortgage insurance premiums after year 11. It is challenging for the insurer to hedge potential losses after ten years. Therefore, we design a second type of crossover bond (Type II), the terms of which are virtually identical to those of the original crossover bond, with one main exception: it pays a fixed coupon rate equal to the ten-year yield rate $(3.13$ per cent) for the first ten years. With the three-dimensional lattice method, we provide in Table 4 the fair coupon rates of the principal-guaranteed crossover bonds with different times to maturities. Similar to the Type I crossover bond, both the coupon rate and the markup increase as the time to maturity increases. In addition, the markup is significantly larger than that of the Type I crossover bond. Therefore, the Type II crossover bond provides a different risk profile for bond investors. 


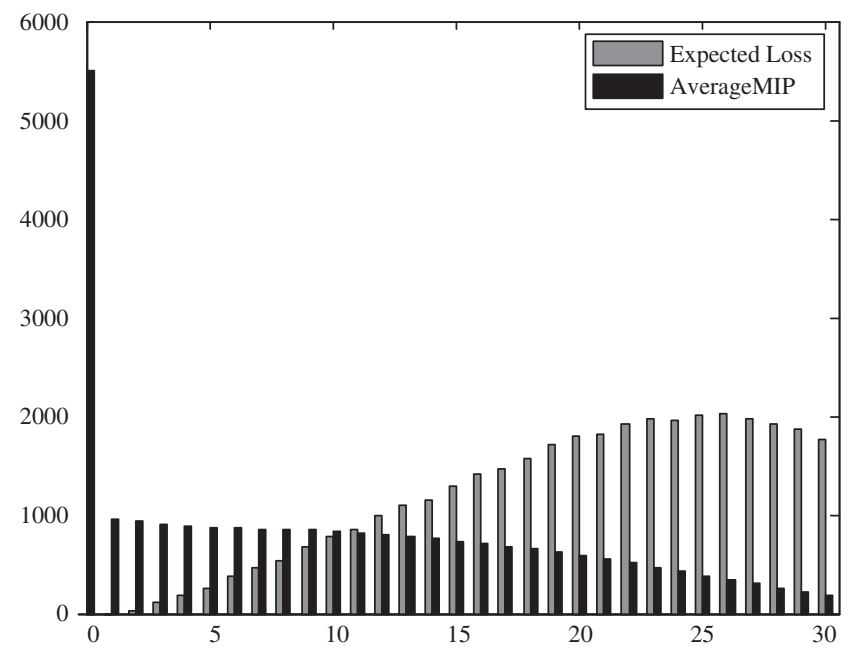

Figure 8. Expected losses and average mortgage insurance premiums.

Table 4 Fair coupon rates of crossover bonds (Type II)

\begin{tabular}{|c|c|c|c|c|c|}
\hline \multirow{2}{*}{$\begin{array}{l}\text { Time to } \\
\text { maturity }\end{array}$} & \multicolumn{3}{|c|}{ Coupon rate } & \multirow{2}{*}{$\begin{array}{c}\text { Corresponding zero } \\
\text { rate }(\%)\end{array}$} & \multirow{2}{*}{$\begin{array}{c}\text { Markup } \\
\text { (bps) }\end{array}$} \\
\hline & $\begin{array}{c}1-10 \text { years } \\
(\%)\end{array}$ & $\begin{array}{c}\text { Actual loss }>\text { Expected } \\
\text { loss }(\%)\end{array}$ & $\begin{array}{c}\text { Actual loss } \leqq \text { Expected } \\
\operatorname{loss}(\%)\end{array}$ & & \\
\hline 15 & 3.30 & 0.50 & 5.42 & 3.72 & +170.87 \\
\hline 20 & 3.30 & 0.50 & 6.26 & 4.13 & +212.63 \\
\hline 25 & 3.30 & 0.50 & 6.40 & 4.24 & +216.56 \\
\hline 30 & 3.30 & 0.50 & 6.52 & 4.34 & +217.77 \\
\hline
\end{tabular}

\section{Conclusion}

In addition to government-sponsored social security systems and employer-sponsored retirement plans, reverse mortgages have become remarkably popular because they allow retirees to convert their substantial home equities into either a lump sum or an annuity and to remain in their homes until they die, sell or vacate their homes to live elsewhere. In the United States, only an estimated 2 per cent of possible reverse mortgage borrowers take advantage of these loans under government-guaranteed programmes. To offset future pension and senior care costs, many countries need to find ways to increase this acceptance rate for reverse mortgage loans. From the insurer's perspective, reverse mortgages involve a range of risks, including housing price, interest rate and longevity risks. In this article, with full consideration of all three forms of risk, we provide a three-dimensional lattice method that simultaneously captures the evolution of housing prices and short-term interest rates, and numerically calculates fair values for reverse mortgages. 
642

Based on an actuarial equivalence principle, the premium structure of reverse mortgages is determined according to when the present value of expected premiums is equal to the present value of expected losses. However, the insurer incurs an unexpected loss if actual losses are larger than expected losses. To hedge unexpected losses, we design two types of principal-guaranteed crossover bonds, whose payoff structures are related to actual losses and expected losses. Therefore, through crossover bonds, reverse mortgage insurers can partly transfer the crossover risk to bond investors.

Since Clark's ${ }^{33}$ early work, it has been widely recognised that the dynamics of asset returns present some commonly observed statistical properties-or stylised empirical facts in financial econometrics literature. ${ }^{34}$ Therefore, the dynamics of housing returns may not be adequately described by GBM with constant drift and volatility. From our numerical analysis, we find that the impact of housing price volatility is more important than that of interest rate volatility on pricing reverse mortgages; therefore, it would be interesting to incorporate stylised facts with housing price processes, such as exponential Lévy processes or GARCH Lévy models for pricing reverse mortgages. Furthermore, using the Lee-Carter or other mortality models while considering mortality improvement as an appropriate predictor of mortality can decrease the LTV ratio. If a financial institution aims to maximise the LTV ratio to increase market acceptance of non-government-guaranteed reverse mortgage programmes, it might adopt a model with higher mortality rates or higher withdrawal rates.

\section{References}

Bishop, T.B and Shan, H. (2008) 'Reverse mortgages: A closer look at HECM loans.' National Bureau of Economic Research, http://www.nber.org/programs/ag/rrc/08-Q2\%20Bishop,\%20Shan\%20FINAL.pdf

Black, F. and Karasinski, P. (1991) 'Bond and option pricing when short-term rates are lognormal', Financial Analysts Journal 47(4): 52-59.

Black, F., Derman, E. and Toy, W. (1990) 'A one-factor model of interest rates and its application to Treasury bond options', Financial Analysts Journal 46(1): 33-39.

Blake, D. (2003) 'Reply to survivor bonds: A comment on Blake and Burrows', Journal of Risk and Insurance 70(2): 349-351.

Blake, D. and Burrows, W. (2001) 'Survivor bonds: Helping to hedge mortality risk', Journal of Risk and Insurance 68(2): 339-348.

Boehm, T.P. and Ehrhardt, M.C. (1994) 'Reverse mortgages and interest rate risk', Journal of the American Real Estate and Urban Economics Association 22(2): 387-408.

Chen, H., Cox, S. and Wang, S. (2010) 'Is the Home Equity Conversion Mortgage in the United States sustainable? Evidence from pricing mortgage insurance premiums and non-recourse provisions using the conditional Esscher transform', Insurance: Mathematics and Economics 46(2): 371-384.

Chinloy, P. and Megbolugbe, I.F. (1994) 'Reverse mortgage: Contracting and crossover risk', Journal of American Real Estate and Urban Economics Association 22(2): 367-386.

Clark, P.K. (1973) 'A subordinated stochastic process model with finite variance for speculative prices', Econometrica 41: 135-156.

Clewlow, L and Strickland, C. (1998) Implementing Derivatives Models, London: John Wiley and Sons.

Cont, R. (2001) 'Empirical properties of asset returns: Stylized facts and statistical issues', Quantitative Finance 1(1): 1-14.

\footnotetext{
${ }^{33}$ Clark (1973).

${ }^{34}$ Cont (2001).
} 
Cox, J.C., Ingersoll, J. and Ross, S.A. (1985) 'A theory of the term structure of interest rates', Econometrica 53: 385-407.

Cox, J.C., Ross, S.A. and Rubinstein, M. (1979) 'Option pricing: A simplified approach', Journal of Financial Economics 7(3): 229-263.

Cowley, A. and Cummins, J.D. (2005) 'Securitization of life insurance assets and liabilities', Journal of Risk and Insurance 72(2): 193-226.

Cunningham, D. and Hendershott, P. (1984) 'Pricing FHA mortgage default insurance', Housing Finance Review 3(4): 373-392.

Denuit, M., Devolder, P. and Goderniaux, A.C. (2007) 'Securitization of longevity risk: Pricing survivor bonds with Wang transform in the Lee-Carter framework', Journal of Risk and Insurance 74(1): 87-113.

Dothan, M. (1978) 'On the term structure of interest rates', Journal of Financial Economics 7: $229-264$.

Hilliard, J.E., Kau, J.B. and Slawson Jr., V.C. (1998) 'Valuing prepayment and default in a fixed-rate mortgage: A bivariate binomial options pricing technique', Real Estate Economics 26(3): 431-468.

Jamshidian, F. (1989) 'An exact bond option formula', Journal of Finance 44(1): 205-209.

Jamshidian, F. (1991) 'Forward induction and construction of yield curve diffusion models', Journal of Fixed Income 1: 62-74.

Kau, J.B., Keenan, D., Muller, W. and Epperson, J. (1992) 'A generalized evaluation model for fixed-rate residential mortgages', Journal of Money, Credit and Banking 24(3): 279-299.

Lee, R.D. (2000) 'The Lee-Carter method for forecasting mortality, with various extensions and applications', North American Actuarial Journal 4(1): 80-93.

Lee, R.D. and Carter, L.R. (1992) 'Modeling and forecasting U.S. mortality', Journal of the American Statistical Association 87(419): 659-675.

Lee, R.D. and Miller, T. (2001) 'Evaluating the performance of the Lee-Carter method for forecasting mortality', Demography 38(4): 537-549.

Lin, Y. and Cox, S.H. (2005) 'Securitization of mortality risks in life annuities', Journal of Risk and Insurance 72(2): 227-252.

Ma, S., Kim, G. and Lew, K. (2007) Estimating Reverse Mortgage Insurer's Risk Using Stochastic Models, paper presented at the Asia-Pacific Risk and Insurance Association 2007 Annual Meeting.

Mitchell, O.S. and Piggott, J. (2004) 'Unlocking housing equity in Japan', Journal of the Japanese and International Economies 18: 7-18.

Phillips, W.A. and Gwin, S.B. (1992) 'Reverse mortgage', Transactions of the Society of Actuaries 44: 289-323.

Rodda, D.T., Lam, K. and Youn, A. (2004) 'Stochastic modeling of federal housing administration home equity conversion mortgages with low-cost refinancing', Real Estate Economics 32(4): 589-617.

Shreve, S. (2004) Stochastic Calculus for Finance II: Continuous Time Models, New York: Springer Verlag.

Szymanoski Jr., E. (1994) 'Risk and the Home Equity Conversion Mortgage', Journal of American Real Estate and Urban Economics Association 22(2): 347-366.

Vasicek, O. (1977) 'An equilibrium characterization of the term structure', Journal of Financial Economics 5(2): $177-188$.

Wang, L., Valdez, E.A. and Piggott, J. (2007) ‘Securitization of Longevity Risk in Reverse Mortgages', from http://ssrn.com/abstract $=1087549$, accessed 30 January 2008.

Wang, S.S. (2000) 'A class of distortion operators for pricing financial and insurance risks', Journal of Risk and Insurance 67(1): 15-36.

Yang, T.T., Buist, H. and Megbolugbe, I.F. (1998) 'An analysis of the ex-ante probabilities of mortgage prepayment and default', Real Estate Economics 26(4): 651-676.

\section{About the Authors}

Hong-Chih Huang is Professor and Head of the Department of Risk Management and Insurance at National Chengchi University in Taiwan. He received his $\mathrm{PhD}$ at the Department of Actuarial Mathematics and Statistics at Heriot-Watt University in 
the U.K. His research interests cover asset liability management, asset allocation, longevity risk and pension.

Chou-Wen Wang is Associate Professor at the Department of Risk Management and Insurance at National Kaohsiung First University of Science and Technology in Taiwan. He received his $\mathrm{PhD}$ at the Department of Money and Banking at National Chengchi University in Taiwan and his Masters degree at the Department of Finance at National Sun Yat-Sen University in Taiwan. His research interests cover option pricing, financial risk management, equity return modelling, credit risk modelling, mortality modelling and securitisation.

Yuan-Chi Miao works at Cathay Life Insurance Co., Ltd. She received her Masters degree at the Department of Risk Management and Insurance, at National Chengchi University in Taiwan.

\section{Appendix A}

Proof of Eq. (7)

Using Ito's Lemma, we have

$$
d \ln H_{t}=\left(r_{t}-\frac{1}{2} \sigma_{H}^{2}\right) d t+\sigma_{H}\left(\rho_{H r} d W_{t}^{r}+\sqrt{1-\rho_{H r}^{2}} d W_{t}^{H}\right)
$$

Or equivalently,

$$
\ln H_{T}=\ln H_{0}+\int_{0}^{T}\left(r_{s}-\frac{1}{2} \sigma_{H}^{2}\right) d s+\sigma_{H}\left(\rho_{H r} W_{T}^{r}+\sqrt{1-\rho_{H r}^{2}} W_{T}^{H}\right) .
$$

Therefore,

$$
\begin{aligned}
& E_{Q}\left[H(T) \exp \left(-\int_{0}^{T} r_{s} d s\right)\right] \\
& \quad=H_{0} E_{Q}\left[\exp \left(\sigma_{H}\left(\rho_{H r} W_{T}^{r}+\sqrt{1-\rho_{H r}^{2}} W_{T}^{H}\right)-\frac{1}{2} \sigma_{H}^{2} T\right)\right] .
\end{aligned}
$$

Because $\sigma_{H}\left(\rho_{H r} W_{T}^{r}+\sqrt{1-\rho_{H r}^{2}} W_{T}^{H}\right)$ follows a normal distribution with zero mean and variance equal to $\sigma_{H}^{2} T$, we obtain $E_{Q}\left[H(T) \exp \left(-\int_{0}^{T} r_{s} d s\right)\right]=H_{0}$. This completes the proof of Eq. (7). 


\section{Appendix B}

\section{Constructing the binomial spot-rate tree}

As shown by Black et al. ${ }^{10}$ and Clewlow and Strickland, ${ }^{35}$ the procedure to determine the BDT model based on the yield curve and yield rate volatilities is as follows: Let node $(1,1)$ be denoted by $U$ and node $(1,-1)$ be denoted by $D$. Let $P_{U}(i)$ and $P_{D}(i)$ for $i=1, \ldots, N$ be the discount function evaluated at nodes $U$ and $D$, respectively. Let $\sigma_{R}(i)$ be the volatility of the yield on the zero coupon bond maturing at time $i \Delta t$. Then $Q_{U, i, j}\left(Q_{D, i, j}\right)$ is the value, as seen from node $U(D)$, of a security that pays off US\$1 if node $(i, j)$ is reached and $\$ 0$ otherwise. By definition, $Q_{U, i, j}=1$ and $Q_{D, i, j}=1$. The risk-neutral probabilities of the binomial branches for the BDT model are assumed to be 0.5 . The value at the initial times are $\phi(0)=r_{0}(0), \sigma_{0}^{r}=\sigma_{R}(1)$ and $d_{0,0}^{r}=1 /\left(1+r_{0}(0) \Delta t\right)$.

The first step for constructing the BDT model is to determine $P_{U}(i)$ and $P_{D}(i)$ for $i=2, \ldots, N$ using Eq. (5):

$$
\frac{1}{1+r_{0}(0) \Delta t}\left(0.5 P_{U}(i)+0.5 P_{D}(i)\right)=P(0, i \Delta t),
$$

where

$$
\begin{aligned}
P_{U}(i+1)= & \sum_{j} Q_{U, i, j} \frac{1}{1+r_{i \Delta t}(j) \Delta t} \\
= & \sum_{j} Q_{U, i, j} \frac{1}{1+\phi(i) \exp \left(\sigma_{i \Delta t}^{r} j \sqrt{\Delta t}\right) \Delta t} \\
& j=-i+2, \ldots, i
\end{aligned}
$$

and

$$
\begin{aligned}
P_{D}(i+1)= & \sum_{j} Q_{D, i, j} \frac{1}{1+r_{i \Delta t}(j) \Delta t} \\
= & \sum_{j} Q_{D, i, j} \frac{1}{1+\phi(i) \exp \left(\sigma_{i \Delta t}^{r} j \sqrt{\Delta t}\right) \Delta t} \\
& j=-i, \ldots, i-2 .
\end{aligned}
$$

To match the initial volatility curve, we have

$$
\sigma_{R}(i) \sqrt{\Delta t}=\frac{1}{2} \ln \left(\frac{\ln P_{U}(i)}{\ln P_{D}(i)}\right) .
$$

\footnotetext{
${ }^{35}$ Clewlow and Strickland (1998).
} 
Therefore, substituting Eq. (B.4) into Eq. (B.1) yields

$$
P_{U}(i)+P_{U}(i)^{\exp \left(-2 \sigma_{R}(i) \sqrt{\Delta t}\right)}=2 P(0, i \Delta t)\left(1+r_{0}(0) \Delta t\right) .
$$

According to Eq. (B.5), we can derive $P_{U}(i)$ and $P_{D}(i)$ for $i=2, \ldots, N$. The second step is to generate $Q_{U, i, j}$ and $Q_{D, i, j}$, as follows:

$$
Q_{U, i, j}=0.5\left(Q_{U, i-1, j-1} d_{i-1, j-1}^{r}+Q_{U, i-1, j+1} d_{i-1, j+1}^{r}\right),
$$

and

$$
Q_{D, i, j}=0.5\left(Q_{D, i-1, j-1} d_{i-1, j-1}^{r}+Q_{D, i-1, j+1} d_{i-1, j+1}^{r}\right) .
$$

Using these two discount functions, we can simultaneously solve $\phi(i)$ and $\sigma_{i \Delta t}^{r}$ according to Eqs. (B.2) and (B.3). Finally, the spot rates and discount factors for all nodes $j$ at time $i \Delta t$ are given by $r_{i \Delta t}(j)=\phi(i) \exp \left(\sigma_{i \Delta t}^{r} j \sqrt{\Delta t}\right)$ and $d_{i, j}^{r}=1 /\left(1+r_{i \Delta t}(j) \Delta t\right)$. This completes the procedure for building the binomial spot-rate tree.

\section{Appendix C}

\section{Constructing a binomial housing price tree}

In view of Eq. (A.2), when the spot rate at time $i \Delta t$ is $r_{i \Delta t}(j)$, the housing price dynamic under the risk-neutral measure $Q$ is given by

$$
\begin{aligned}
& \ln \left(\frac{H_{(i+1) \Delta t}}{H_{i \Delta t}}\right)=\left(r_{i \Delta t}(j)-\frac{1}{2} \sigma_{H}^{2}\right) \Delta t \\
& \quad+\sigma_{H}\left(\rho_{H r}\left(W_{(i+1) \Delta t}^{r}-W_{i \Delta t}^{r}\right)+\sqrt{1-\rho_{H r}^{2}}\left(W_{(i+1) \Delta t}^{H}-W_{i \Delta t}^{H}\right)\right)
\end{aligned}
$$

In the BDT model, we replace $W_{i \Delta t}^{r}$ by $\sum_{k=1}^{i} X_{k} \sqrt{\Delta t}$; hence, Eq. (C.1) can be rewritten as

$$
\begin{aligned}
& \ln \left(\frac{H_{(i+1) \Delta t}}{H_{i \Delta t}}\right)=\left(r_{i \Delta t}(j)-\frac{1}{2} \sigma_{H}^{2}\right) \Delta t \\
& \quad+\sigma_{H}\left(\rho_{H r} X_{i+1} \sqrt{\Delta t}+\sqrt{1-\rho_{H r}^{2}}\left(W_{(i+1) \Delta t}^{H}-W_{i \Delta t}^{H}\right)\right) .
\end{aligned}
$$

We construct the binomial tree by matching the first two moments of Eq. (C.2) with the tree's parameters, as follows:

$$
\begin{aligned}
& E\left(\ln \left(\frac{H_{(i+1) \Delta t}}{H_{i \Delta t}}\right) \mid r_{i \Delta t}(j), X_{i+1}\right) \\
& =\left(r_{i \Delta t}(j)-\frac{1}{2} \sigma_{H}^{2}\right) \Delta t+\sigma_{H} \rho_{H r} X_{i+1} \sqrt{\Delta t} \\
& =P_{r_{i \Delta t}(j), X_{i+1}}^{H} \ln u+\left(1-P_{r_{i \Delta t}(j), X_{i+1}}^{H}\right) \ln d .
\end{aligned}
$$




$$
\begin{aligned}
& E\left(\left[\ln \left(\frac{H_{(i+1) \Delta t}}{H_{i \Delta t}}\right)\right]^{2} \mid r_{i \Delta t}(j), X_{i+1}\right) \\
& \quad=\left(\left(r_{i \Delta t}(j)-\frac{1}{2} \sigma_{H}^{2}\right) \Delta t+\sigma_{H} \rho_{H r} X_{i+1} \sqrt{\Delta t}\right)^{2}+\sigma_{H}^{2}\left(1-\rho_{H r}^{2}\right) \Delta t \\
& \quad=\sigma_{H}^{2} \Delta t=P_{r_{i \Delta t}^{H}(j), X_{i+1}}(\ln u)^{2}+\left(1-P_{r_{i \Delta t}^{H}(j), X_{i+1}}\right)(\ln d)^{2},
\end{aligned}
$$

where we use the fact that $(\Delta t)^{n}=0$ for $n>1$ and $X_{i+1}^{2}=1$. Using the series expansion $e^{x}=1+x+x^{2} / 2+\cdots$ and ignoring the higher powers of $\Delta t$, we attain one solution of Eqs. (C.3) and (C.4) in the form of Eqs. (23) and (24). This completes the proof of Proposition 1 . 